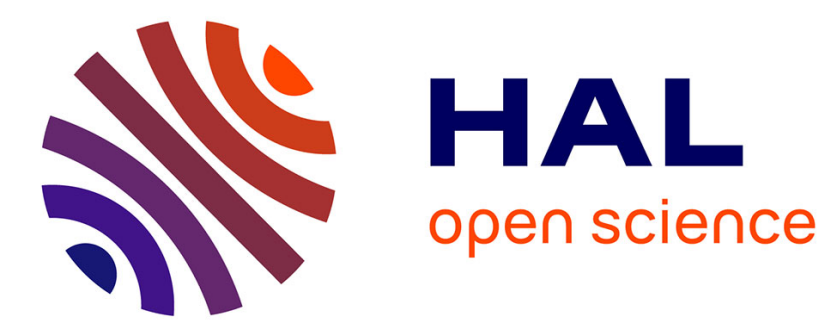

\title{
Controlling foam stability with the ratio of myristic acid to choline hydroxide
}

Audrey Arnould, Fabrice Cousin, Anniina Salonen, Arnaud Saint-Jalmes, Adrian Perez, Anne-Laure Fameau

\section{- To cite this version:}

Audrey Arnould, Fabrice Cousin, Anniina Salonen, Arnaud Saint-Jalmes, Adrian Perez, et al.. Controlling foam stability with the ratio of myristic acid to choline hydroxide. Langmuir, 2018, 34 (37), pp.11076-11085. 10.1021/acs.langmuir.8b02261 . hal-01868076

\section{HAL Id: hal-01868076 https://hal.science/hal-01868076}

Submitted on 18 Sep 2018

HAL is a multi-disciplinary open access archive for the deposit and dissemination of scientific research documents, whether they are published or not. The documents may come from teaching and research institutions in France or abroad, or from public or private research centers.
L'archive ouverte pluridisciplinaire HAL, est destinée au dépôt et à la diffusion de documents scientifiques de niveau recherche, publiés ou non, émanant des établissements d'enseignement et de recherche français ou étrangers, des laboratoires publics ou privés. 


\section{Controlling foam stability with the ratio of myristic acid to choline hydroxide}

Audrey Arnould ${ }^{1}$, Fabrice Cousin ${ }^{2}$, Anniina Salonen ${ }^{3}$, Arnaud Saint-Jalmes ${ }^{4}$, Adrian Perez ${ }^{5}$ and Anne-Laure Fameau ${ }^{1 *}$

1) Biopolymères Interactions Assemblages INRA, la Géraudière, 44316 Nantes, France.

2) Laboratoire Léon-Brillouin, CEA Saclay, 91191 Gif-sur-Yvette CEDEX, France.

3) Laboratoire de Physique des Solides, UMR 8502, Université of Paris Sud, 91405 Orsay, France.

4) Institut de Physique de Rennes, UMR CNRS 6251 -Université Rennes 1, Rennes, France.

5) Grupo de Biocoloides, Instituto de Tecnología de Alimentos, Universidad Nacional del Litoral, 1 de Mayo 3250 (3000), Santa Fe, Argentina.

\section{Corresponding author:}

Anne-Laure Fameau, email: anne-laure.fameau@nantes.inra.fr

\section{Graphical Abstract:}

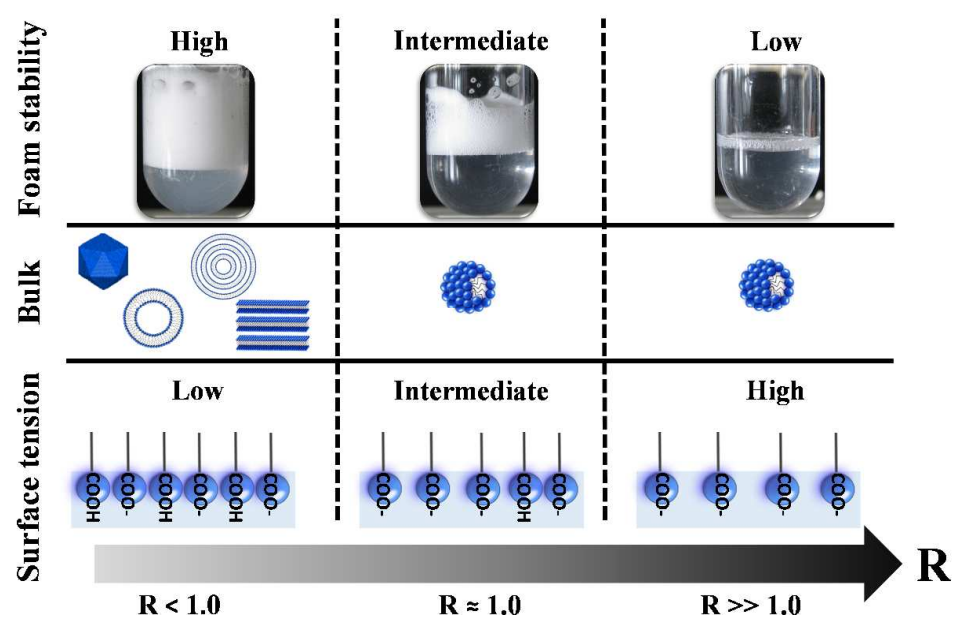




\begin{abstract}
:
The interfacial and foam properties of a model system based on the mixture between myristic acid and choline hydroxide have been investigated as a function of the molar ratio (R) between these two components and temperature. The aim of this study was to obtain insight on the links between the self-assemblies in bulk and in the foam liquid channels, the surfactants packing at the interface, the resulting foam properties and stability. A multi-scale approach was used combining Small Angle Neutron Scattering, Specular Neutron Reflectivity, surface tension measurements, and photography. We highlighted three regimes of foam stability in this system by modifying $\mathrm{R}$ : high foam stability for $\mathrm{R}<1$, intermediate at $\mathrm{R} \sim 1$ and low for $\mathrm{R}>1$. The different regimes come from the $\mathrm{pH}$ variations in bulk linked to R. The pH plays a crucial role at the molecular scale by setting the ionization state of the myristic acid molecules adsorbed at the gas-liquid interface, which in turn controls both the properties of the monolayer and the stability of the films separating the bubbles. The main requirement to obtain stable foams is to set the $\mathrm{pH}$ close to the $\mathrm{pKa}$ in order to have a mixture of protonated and ionized molecules giving rise to intermolecular hydrogen bonds. As a result, a dense monolayer is formed at the interface with a low surface tension. $\mathrm{R}$ also modifies the structure of self-assembly in bulk and therefore within the foam, but such a morphological change has only a minor effect on the foam stability. This study confirms that foam stability in surfactant systems having a carboxylic acid as polar head group is mainly linked to the ionization state of the molecules at the interface.
\end{abstract}

Keywords: fatty acid, molar ratio, hydrogen bond, foam stability, surface 


\section{Introduction:}

Fatty acid soaps have been known for over 2000 years as surfactants to produce foams and emulsions, and are used since a long time in laundry and personal care products. ${ }^{1-4}$ Fatty acids are anionic surfactants with a carboxylic acid as polar headgroup. There are plenty of reports available on the foaming and emulsifying behavior of fatty acids as a function of the pH and ionic strength. ${ }^{5-8}$ The first one was published in 1944 by Miles and Ross, who studied the stability of foams produced from fatty acids. ${ }^{9}$ Then, various studies have shown that the fatty acids' bulk self-assemblies can affect the macroscopic properties such as emulsifying and foaming properties. ${ }^{10-17}$ From these studies, lamellar phases or vesicles seem to be the most efficient self-assembled structures to stabilize foams and emulsions in contrary to spherical micelles. ${ }^{14,18,19}$ The foam stability for fatty acid soaps would be linked to the size of the self-assembled structures as already highlighted in the case of protein aggregates. ${ }^{20,21}$ Recently C. Stubenrauch et al. has pointed out that when surfactants have a polar headgroup with a hydrogen bond donor and a proton acceptor, stable foams can only be generated when hydrogen bonds can be formed between the head groups at the interface. ${ }^{22-24} \mathrm{Up}$ to now, most of the studies on fatty acid systems have been performed by only looking at the selfassembled structure in bulk or at the interfacial properties to try to understand the mechanisms that drive the destabilization of foam. A global multiscale study needs to be performed at all relevant scales of the system from the molecular scale to the macroscopic scale to increase our understanding on these destabilization phenomena. The question related to the main parameters governing foam stability, not only concerns the fatty acid soap systems, but more widely all the surfactant systems and remains an open question for the foam community. ${ }^{20,25-}$ ${ }^{28}$ For instance, Ferreira et al., have studied recently these issues for a catanionic surfactant system, and have shown that the self-assembled structure in bulk was not the relevant parameter to predict the foam stability. ${ }^{29}$

In this study, our goal was to make a full characterization of a model fatty acid soap system, respectively at the molecular scale, at the scale of the air/water interface, and finally at the mesoscopic scale of the self-assembled structures inside the foam liquid channels, in order to highlight the main parameters governing the foam stability at the macroscopic scale. To achieve this goal, we first selected a model fatty acid soap system already described in a previous work showing a broad polymorphism in bulk: the myristic acid dispersed in aqueous solution by using choline hydroxide as counterion. ${ }^{30}$ Choline is a quaternary ammonium ion of biological origin, which is physiologically and environmentally harmless, and is very 
efficient to disperse fatty acids. ${ }^{31-34}$ In this model system the self-assembly in bulk is widely tuned by the molar ratio $\mathrm{R}$, which modifies the $\mathrm{pH}$ of the aqueous solution. By tuning $\mathrm{R}$, we modify the quantity of hydroxide ions in bulk. Thus, an increase of $\mathrm{R}$ leads to a $\mathrm{pH}$ increase due to the addition of hydroxide ions with the choline cation. $\mathrm{R}$ sets the $\mathrm{pH}$ of the aqueous solution, which in turns governs the ionization state of the fatty acids and the headgroup interactions leading to the broad polymorphism in bulk. In fatty acid systems, different studies have clearly evidenced the effect of the molar ratio in bulk. ${ }^{1,35-41}$ For the myristic acid/choline hydroxide system, facetted vesicles, unilamellar and multilamellar vesicles, lamellar phases and spherical micelles have been observed as a function of $\mathrm{R}$.

In order to investigate the correlation between the bulk self-assembly, the variation of the interfacial properties and of the foam properties as a function of $\mathrm{R}$, we performed a multiscale study by combining experiments and techniques at different length scales to explain the macroscopic foaming properties, and especially foam stability. The aggregated structures confined inside the foam liquid channels were investigated using Small Angle Neutron Scattering. The surface properties were determined by coupling surface tension and neutron reflectivity measurements.

\section{Materials and Methods}

\section{Sample preparation}

The two main components were purchased from Sigma Aldrich and were used as received: myristic acid (purity $>99 \%$ ) and choline hydroxide (46\% wt in water). To prepare the myristic acid dispersion in the presence of the choline hydroxide, we first weighed the fatty acid powder to which ultrapure water was added to reach the final concentration fixed at $4.4^{*} 10^{-2}$ mol. $\mathrm{L}^{-1}$, which corresponds to $1 \%$ weight in water. In the second step, we prepared the choline hydroxide solution at $1 \mathrm{~mol} . \mathrm{L}^{-1}$ in ultrapure water. Then, this counter-ion solution was added to reach the desired molar ratio defined as $\mathrm{R}=\mathrm{n}_{\text {choline hydroxide }} / \mathrm{n}_{\text {myristic acid }}$ with $n$ the molar concentration in mol. $\mathrm{L}^{-1}$. In this study, the concentration of myristic acid was kept at $4.4^{*} 10^{-2}$ mol.L $\mathrm{L}^{-1}$ and only the concentration of counter-ion was modified to vary R. To fully disperse the fatty acid powder in water in the presence of the counter-ion, the mixture was heated to $75^{\circ} \mathrm{C}$ during 5 minutes and then cooled down to room temperature before being frozen at $-18^{\circ} \mathrm{C}$. This cycle was repeated at least two times to ensure the complete dispersion of the fatty acid powder. All the samples were stored at $-18^{\circ} \mathrm{C}$. Before performing any 
experiment of characterization, all samples were heated again at $75^{\circ} \mathrm{C}$ during 5 minutes and cooled to room temperature.

\section{Foam production and determination of drainage kinetics}

The foams were produced by two techniques: hand-shaking and gas bubbling. Measurements were performed at $15^{\circ} \mathrm{C}, 25^{\circ} \mathrm{C}$ and $35^{\circ} \mathrm{C}$ and were carried out three times for reproducibility.

In the first method, the foams were produced by vigorous hand-shaking of cylindrical graduated plastic containers of $15 \mathrm{~mL}$ (15 mm internal diameter, $118 \mathrm{~mm}$ height) filled with $4 \mathrm{~mL}$ of fatty acid dispersion. The mixture was agitated for $60 \mathrm{sec}$ and all foam samples were produced by the same operator. The evolution of the foam volume was evaluated by naked eye and measured using the graduation of the containers. Secondly, we also produced foams by bubbling gas into the fatty acid solution using a Foamscan (I.T.Concept, France). Foams were generated in a glass column $21 \mathrm{~mm}$ in diameter by bubbling nitrogen gas through a porous glass disc with a 10-16 $\mu \mathrm{m}$ pore size and a diameter of $3 \mathrm{~mm}$. The gas flow rate was fixed at $45 \mathrm{~mL} \cdot \mathrm{min}^{-1}$. The final foam volume was fixed at $45 \mathrm{~mL}$. Once this foam volume was reached, the gas flow stopped automatically. A camera recorded pictures of foams every $100 \mathrm{sec}$. The foam formation and stability was monitored by image analysis. To quantify the volume of liquid drained out of the foam at the bottom of the column, conductivity measurements were performed by using electrodes. Before measurements, solutions of myristic acid and choline were introduced inside the glass column and left for $30 \mathrm{~min}$ to equilibrate to the required temperature before producing the foam.

\section{Small Angle Neutron Scattering (SANS)}

We performed SANS experiments on the PACE spectrometer at the Laboratoire Léon Brillouin (Saclay, France). We chose three configurations with a significant overlap between them to get a Q-range spanning from $5.10^{-3}$ to $3.10^{-1} \AA^{-1}$ (respectively $5 \AA$ at $1 \mathrm{~m}, 5 \AA$ at $4.7 \mathrm{~m}$ and $13 \AA$ at $4.7 \mathrm{~m})$. The temperature was controlled within $\pm 0.2^{\circ} \mathrm{C}$. The neutron wavelength was set to the desired value with a mechanical velocity selector $(\Delta \lambda / \lambda \approx 0.1)$. Standard procedures were applied by the PASINET software to correct the averaged spectra for empty quartz cell, background noise, and detector efficiency contributions in order to obtain scattering in $\mathrm{cm}^{-1}$. The incoherent scattering from solvent was then subtracted afterwards. ${ }^{42}$ In order to ensure a good contrast between the fatty acids and the solvent, as well as good contrast between air and solvent in experiments with foams, the dispersions were made in 
deuterated water $\left(\mathrm{D}_{2} \mathrm{O}\right)$ as solvent. ${ }^{43}$ To study foams by SANS, we produced the foam by using two $10 \mathrm{~mL}$ syringes connected by a plastic tube junction. ${ }^{44}$ The first syringe contained $5 \mathrm{~mL}$ of the initial fatty acid/choline hydroxide dispersion prepared with $\mathrm{D}_{2} \mathrm{O}$ and the second was filled with $3 \mathrm{~mL}$ of air. Foams were produced by pushing alternatively the plungers of both syringes several times.

The foams were left to drain during $5 \mathrm{~min}$ and the drained liquid was collected into a flat quartz cells. The drained foams were put in a flat quartz cells with a $2 \mathrm{~mm}$ optical path length by using a needle to introduce carefully the foam inside the cell. A first foam was produced for the measurement at the two configurations corresponding to large and medium $\mathrm{Q}$ for which the time acquisition is fast (45 min overall) and a second one similar to the first one was used for measurement at small Q with a longer time of acquisition (60 min). We used this procedure to ensure that the foam evolution was slow on the time-scale of the SANS measurements.

\section{Specular Neutron Reflectivity}

Specular neutron reflectivity (SNR) experiments were performed on the horizontal time-offlight reflectometer EROS at the Laboratoire Léon Brillouin (Saclay, France). The horizontal collimated neutron beam was deflected by a neutron super mirror by an angle of $0.75^{\circ}$ on the sample to collect data at a fixed incidence angle of $1.495^{\circ}$. By using a neutron white beam covering wavelength from 3 to $25 \AA$, it was possible to measure the reflectivity coefficient $\mathbb{R}$ in a Q-range lying between $5.10^{-3}$ and $3 \cdot 10^{-1} \AA^{-1}$. The sample was placed in a sealed cell with two quartz windows allowing the passage of neutrons and avoiding the exchange between $\mathrm{D}_{2} \mathrm{O}$ and $\mathrm{H}_{2} \mathrm{O}$ from the atmosphere. Measurements were performed at ambient pressure and temperature. The acquisition of the data was recorded for 16 hours with slices of 2 hours. Samples were prepared by mixing hydrogenated fatty acid and choline hydroxide in deuterated water to ensure a good contrast between the fatty acids and the solvent, and the airwater interfaces and the solvent. The reflectivity curves corresponding to the analytical models presented within the text were calculated by the optical matrix method with a slicing of the scattering length density profiles in slabs of $10 \AA$. The experimental resolution of the spectrometer was taken into account in the calculation. The respective calculations of the scattering length density (SLD) of myristic acid molecules and $\mathrm{D}_{2} \mathrm{O}$ give $\mathrm{N}_{\mathrm{b}}=-0.5^{*} 10^{-6} \AA^{-2}$ and $\mathrm{N}_{\mathrm{b}}=6.39 * 10^{-6} \AA^{-2}$. 


\section{Surface Tension Measurements}

The measurements of the air-solution surface tension as a function of the molar ratio were performed by using the automatized surface tension plate reader Kibron Delta-8 (Kibron, Finland). A volume of $30 \mu \mathrm{L}$ of dispersions was placed on the 96-hole platform. Measurements were performed at $20^{\circ} \mathrm{C}$ after a waiting time of 20 minutes to ensure equilibrium at the air-water interface for all the samples. A calibration was performed by using ultrapure water at $20^{\circ} \mathrm{C}$. Measurements were performed four times for each sample.

\section{$\underline{\text { Results }}$}

1. Phase diagram of the myristic acid/choline hydroxide system in bulk as a function of the molar ratio

We first recall the phase diagram of the myristic acid/choline hydroxide system as a function of $\mathrm{R}$ and temperature determined in a previous study by coupling SANS and TEM experiments (Figure 1). ${ }^{30}$ At low $\mathrm{R}$ below $27^{\circ} \mathrm{C}$, facetted vesicles and disks are present. By increasing $\mathrm{R}$, the facetted objects transform into lamellar phases. All these self-assembled structures transit into spherical vesicles above the phase transition close to $27^{\circ} \mathrm{C}$. The transition from facetted vesicles and lamellar phases into spherical vesicles comes from the melting of the alkyl chain. ${ }^{30}$ Above the phase transition, the bilayer inside the aggregated structure transits from a gel rigid state to a fluid state. By increasing $\mathrm{R}$, spherical micelles appear in bulk in coexistence with lamellar phases or with vesicles. For $R \geq 0.9$ at all temperatures, only spherical micelles are present in bulk. In this system, by tuning $\mathrm{R}$ we modify the $\mathrm{pH}$ of the aqueous solution. In bulk, at $20^{\circ} \mathrm{C}$ for $0.4<\mathrm{R} \leq 1$, the $\mathrm{pH}$ is around 9 close to the $\mathrm{pKa}$ of the myristic acid. For $1<\mathrm{R}<1.2$, the $\mathrm{pH}$ increases from 9 to 11.5 , and reaches 12 for $\mathrm{R}>1.3$ (Figure 3 ). ${ }^{30}$ The molar ratio $\mathrm{R}$ controls the $\mathrm{pH}$ solution, tuning the ionization state of the myristic acid molecules and the interactions between them. It is the modification of both $\mathrm{R}$ and temperature in this fatty acid soap system, which leads to these various self-assembled structures in bulk. 


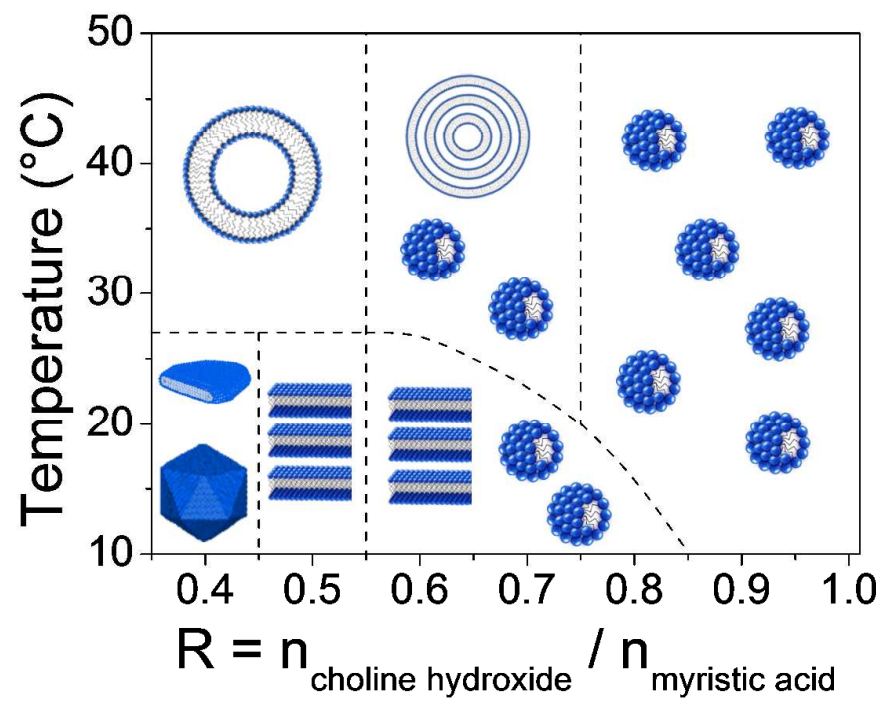

Figure 1: Schematic representation of the phase behavior of the choline hydroxide/myristic acid system in bulk as a function of both $\mathrm{R}$ and temperature as determined in a previous study adapted from reference. ${ }^{30}$

\section{Self-assembly inside the foam liquid channels as a function of the molar ratio}

To produce the foams, we have chosen three molar ratios $\mathrm{R}$ at $15^{\circ} \mathrm{C}$ to be in the presence of three different self-assembled structures in bulk: facetted vesicles $(\mathrm{R}=0.4)$, a mixture between lamellar phases and micelles $(\mathrm{R}=0.8)$ and spherical micelles $(\mathrm{R}=1.0)$. We used SANS experiments to probe the foam and to determine the self-assemblies present inside the foam liquid channels. ${ }^{43}$ The scattered intensities for the foams are shown in Figure 2. In order to compare the self-assembly present in the foam with the one in bulk, we plotted also the bulk scattering spectra from which the foams have been made.

First of all, we compared the respective intensities of bulk and foam samples to determine the liquid fraction for the three foams as described recently in the review from Mikhailovskaya et $a l .{ }^{43}$ For $\mathrm{R}=0.4, \mathrm{R}=0.8$ and $\mathrm{R}=1.0$, the liquid fraction were around 22,24 , and $18 \%$, respectively.

At low $\mathrm{Q}$, on the scattering curves for all the foams, a $\mathrm{Q}^{-4}$ decay was observed arising from the air-water interfaces of the bubbles and is typical of Porod scattering. The intensity can be described by using: $I(q)=2 \pi(\Delta S L D)^{2} S / V q^{-4}$, where $\triangle S L D$ is the difference of scattering length densities between air and the solvent $\mathrm{D}_{2} \mathrm{O}$ and $S / V$ the specific surface corresponding to the amount of gas divided by the water surface per unit volume. ${ }^{43}$ By using such equation to fit our data, we determined the average bubble radius (Figure SI.1). ${ }^{29}$ For $\mathrm{R}=0.4, \mathrm{R}=0.8$ and $\mathrm{R}=1.0$, the average bubbles radii were 62,56 and $72 \mu \mathrm{m}$, 
respectively. For $\mathrm{R}=0.4$, from $\mathrm{Q}=0.01$ to $0.08 \AA^{-1}$, we observed the same $\mathrm{Q}^{-2}$ decay on the SANS spectra of bulk and foams. This $\mathrm{Q}^{-2}$ decay corresponds to the presence of bilayers structure. For $\mathrm{R}=0.4$, facetted vesicles made of bilayers are present in bulk. Thus, the $\mathrm{Q}^{-2}$ decay on the SANS spectra of bulk and foams comes from the scattering of the bilayers of the facetted vesicles. The oscillation at high Q corresponds to the thickness of the bilayers. We observed that it was located at the same position showing that the thickness of the bilayers was the same for the vesicles in bulk and inside the foam liquid channels. The two scattering curves were similar showing no transformation of the facetted vesicles inside the foam. For $\mathrm{R}=0.8$, the scattering curve for the bulk corresponds to the mixture of lamellar phases and spherical micelles as described previously. ${ }^{30}$ On the scattering curve of the foam, in the middle $\mathrm{Q}$ region, we observed three intense sharp peaks located at $\mathrm{Q}=0.0255 \AA^{-1}, \mathrm{Q}=$ $0.0504 \AA^{-1}$, and $\mathrm{Q}=0.0765 \AA^{-1}$. Their positions were exactly in a ratio $1: 2: 3\left(\mathrm{Q}_{0}, 2 \mathrm{Q}_{0}, 3 \mathrm{Q}_{0}\right)$, which indicates the presence of lamellar phases inside the foam liquid channels. The intensity of the peaks was higher than for the bulk dispersion showing that the quantity of lamellar phases was higher inside the foam than for the bulk dispersion. Three hypotheses could explain this difference: (i) during foam generation, the high shear rates could induce the formation of lamellar phases from the micelles, (ii) during foam generation, the foam could be enriched by lamellar phases, or (iii) during the drainage, only the micelles that have small size and high mobility are drained contrary to the lamellar phases which can stay entrapped inside the foam. In order to rule out the hypotheses, a SANS experiment was carried out on the drained liquid. The scattering curve was very similar to the one obtained for the bulk dispersion showing the coexistence of both spherical micelles and lamellar phases. Therefore, we can conclude that most of the lamellar phases remained entrapped inside the foam, and the spherical micelles were free to drain out of the foam with a small quantity of lamellar phases. For $\mathrm{R}=1.0$, the bulk dispersion contained only spherical micelles with a diameter around $18+/-1 \AA^{-1}$. For both the foam and the drained liquid, we observed that the scattering curves were similar to the one obtained for the bulk, especially at high Q where the form factor is probed showing that the micelle size remained the same. Since micelles were composed by ionized fatty acid molecules, they bear an overall negative charge and repel themselves over large distances due to electrostatic repulsions. This gives rise to a broad correlation peak in the medium Q part. From the position of the peak we can estimate the average distance between spherical micelles. In the bulk, the spherical micelles gave rise to a broad correlation peak at $\mathrm{Q}=0.0495 \AA$, which corresponded to a distance (d) between micelles of around $125 \AA(\mathrm{d}=2 \pi / \mathrm{Q})$. For the drained solution, the peak position was slightly shifted to lower $\mathrm{Q}$, 
showing that the mean distance between micelles increased and was around $135 \AA$, i.e. the number of micelles was lower in the drained solution in comparison to the bulk dispersion. We suppose that this comes from the fact that a large quantity of fatty acids remains inside the foam as monomers adsorbed at the interface, compared to the bulk under where they form micelles.

In summary, these SANS results show that the morphology of the self-assembled nanostructures remained the same during the passage from bulk to foam for the three samples probed.
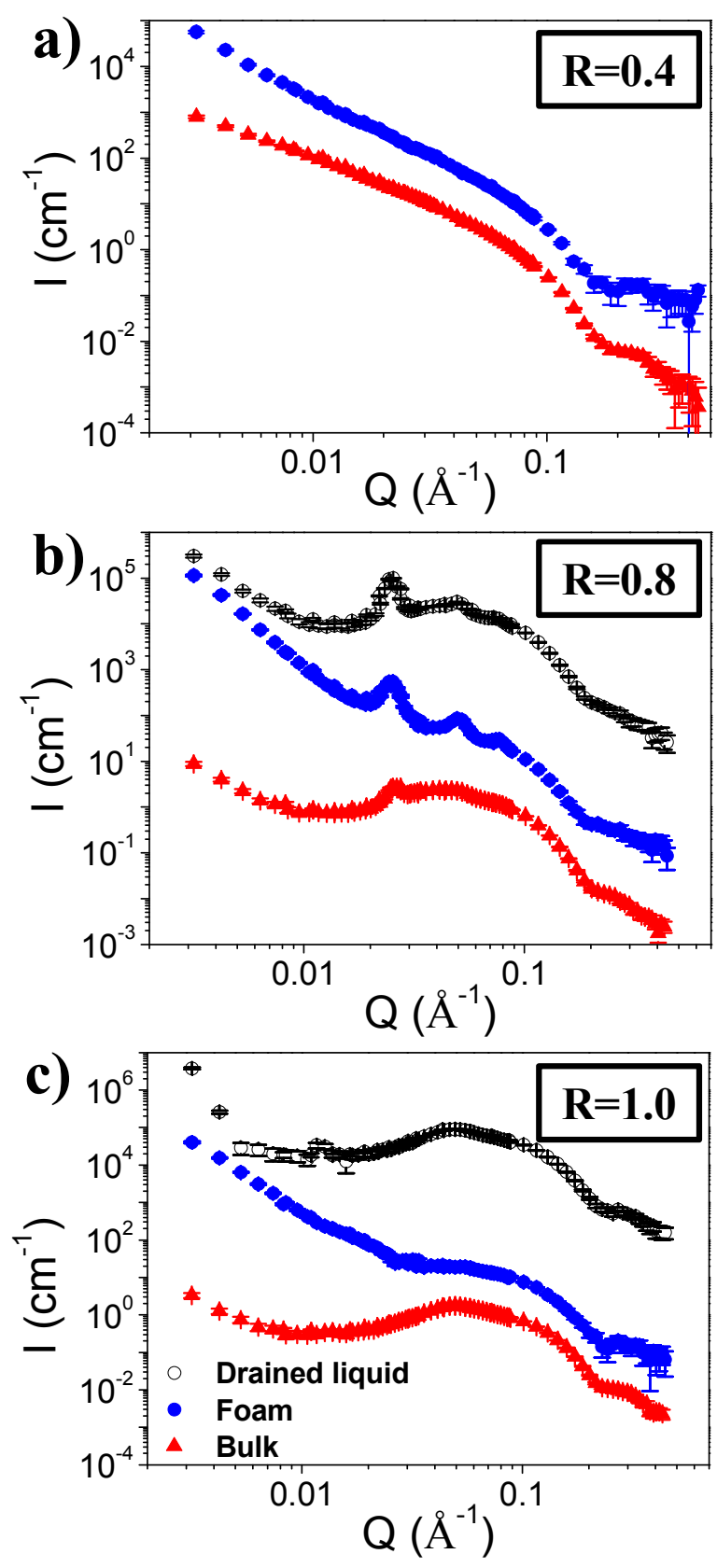
Figure 2: SANS spectra of bulk solutions (red triangle), foams (blue circle) and drained liquid (black empty circle) for (a) $\mathrm{R}=0.4$, (b) $\mathrm{R}=0.8$ and (c) $\mathrm{R}=1.0$. The spectra were shifted in intensity by a factor 100 from each other for clarity.

\section{Effect of the molar ratio on the surface properties}

As our goal was to understand how the foam was stabilized as a function of $\mathrm{R}$, it was mandatory to collect information on how these fatty acid molecules adsorb at the air-water interface. We focused on the surface properties as a function of $\mathrm{R}$ by coupling surface tension and Specular Neutron Reflectivity (SNR) measurements.

We measured the evolution of the surface tension as a function of $\mathrm{R}$ at room temperature to determine the effect on the surface activity of the myristic acid (Figure 3). For $0.4<\mathrm{R}<1$, the surface tension was around $26+/-2 \mathrm{mN} / \mathrm{m}$. For $1 \leq \mathrm{R}<1.2$, the surface tension drastically increased from 26 to $45 \mathrm{mN} / \mathrm{m}$. For $\mathrm{R}>1.2$, the surface tension remained constant around $45+/-1 \mathrm{mN} / \mathrm{m}$. As a function of $\mathrm{R}$, three regimes of surface tension were determined: low, intermediate and high surface tension. By comparing with the $\mathrm{pH}$ evolution as a function of $\mathrm{R}$ determined in a previous study, we observed that the three surface tension regimes followed exactly the evolution of the $\mathrm{pH}$ in bulk (Figure 3 ). ${ }^{30}$

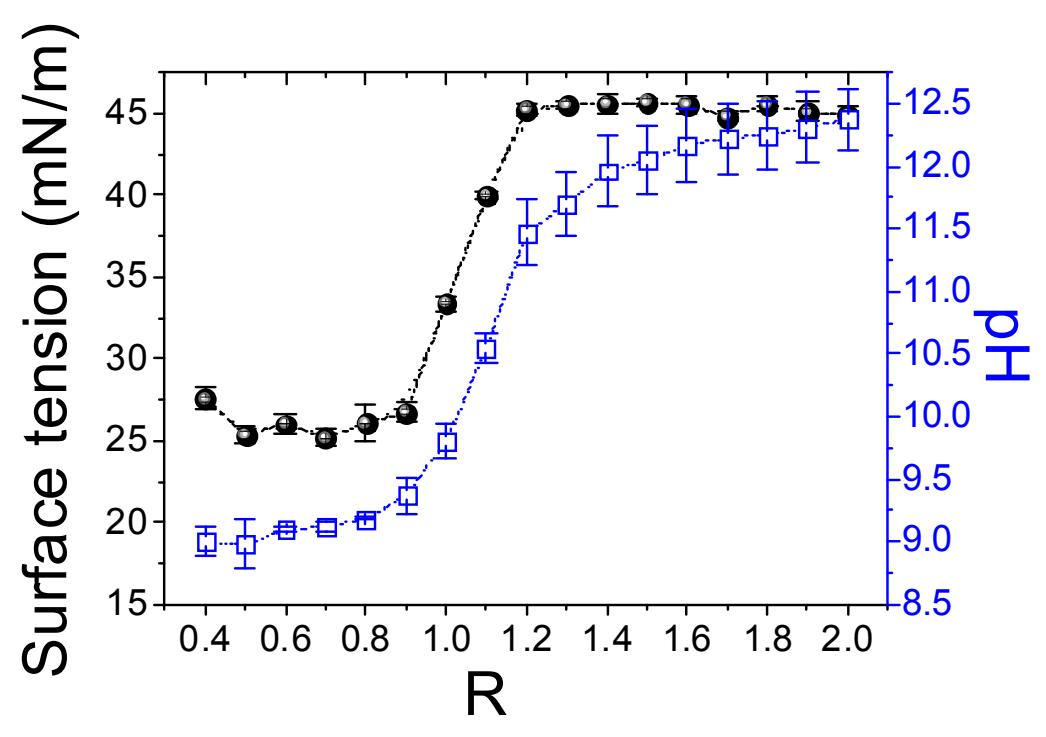

Figure 3: Evolution of the surface tension (black circle) and the $\mathrm{pH}$ (blue square) in the choline hydroxide/myristic acid dispersions as a function of the molar ratio $\mathrm{R}$ at $25^{\circ} \mathrm{C}$. 
Beyond surface tension measurements, various interfacial structures have been described in literature for surfactant systems and neutron reflectivity is a powerful technique to determine them at the air/water interface (surfactant monolayers, lamellar phases, multilamellar vesicles and tubes). ${ }^{45-47}$ We performed SNR experiments at $20^{\circ} \mathrm{C}$ for two molar ratios $\mathrm{R}$ containing self-assembled bilayer structures in bulk: $\mathrm{R}=0.4$ (facetted vesicles) and $\mathrm{R}=0.5$ (lamellar phases). On the SNR curves, we observed a $\mathrm{Q}^{-4}$ scattering decay coming from the pure air/water interface and regular interference fringes showing the presence of a thick layer of myristic acid at the interface (Figure SI.2-3). To fit the SNR data, we used the multilayer model (see SI for the description of data fitting) ${ }^{45,48}$ From these results, we can conclude that the facetted vesicles and the lamellar phases form a lamellar phase structure at the air/water interface adsorbed below a fatty acid monolayer.

\section{Effect of the molar ratio on the foam properties}

We studied the foam properties (foamability and foam stability) as a function of both $\mathrm{R}$ and temperature. The molar ratio was varied from 0.4 to 2.0 and the temperature was fixed at $15^{\circ} \mathrm{C}$ or $35^{\circ} \mathrm{C}$ in order to have different self-assemblies in bulk (Figure 4).

First, we produced foams by bubbling nitrogen gas into each fatty acid dispersions allowing a quantitative description in terms of foamability (how much foam is produced) and foam stability (how the foam evolves). At all temperatures, the foams were formed quickly in around $60+/-5 \mathrm{~s}$ and were made of small homogeneous bubbles (in the range of 50 to 100 $\mu \mathrm{m}$ ) (Table SI.1 and Figure SI.4). Only for R $>1.5$, we observed a slight increase of the time needed to reach the fixed foam volume. Therefore, the foamability was high whatever R since all the gas was encapsulated in the foam at the end of bubbling, with no influence of the selfassembly structure.

To obtain information on the foam stability, we recorded the evolution of the foam volume as a function of time (Figure 4). First, at $15^{\circ} \mathrm{C}$, for $0.4<\mathrm{R}<1.2$, the foam volume was constant during $3600 \mathrm{sec}$ around $40 \mathrm{~cm}^{3}$ (Figure 4.a). These foams can be denoted as stable foams. For $\mathrm{R}=1.3$, the foam volume decreased slowly to reach $30 \mathrm{~cm}^{3}$ after $3600 \mathrm{sec}$. This foam had an intermediate stability. For $\mathrm{R} \geq 1.5$, the foam volume decreased quickly with time. At the end of the experiment, only few bubbles remained inside the foam column. These foams are 
classified as unstable foams. We observed three regimes as a function of R (Figure 4.a). At $25^{\circ} \mathrm{C}$, the self-assemblies are the same as at $15^{\circ} \mathrm{C}$ in bulk and the same evolution of foam stability was observed (Figure SI.5). At $35^{\circ} \mathrm{C}$, three regimes were also obtained (Figure 4.b). For $0.4<\mathrm{R}<1.1$, stable foams were observed with a constant foam volume around $40 \mathrm{~cm}^{3}$ during $3600 \mathrm{sec}$. For $\mathrm{R}=1.2$, the foam had an intermediate stability with a foam volume which decreased slowly with time. For $\mathrm{R} \geq 1.3$, the foams were unstable with a fast foam volume decrease with time. At all temperatures, three regimes of foam stability were observed and we classified them as: stable foam, intermediate stability and unstable foams. Only the limits between the regimes were slightly shifted to lower $\mathrm{R}$ by increasing the temperature. Moreover, the foams were a little less stable at $35^{\circ} \mathrm{C}$ since the foams started to break up at the top after $2400 \mathrm{~s}$, while nothing happened for the foams at $15^{\circ} \mathrm{C}$ and $25^{\circ} \mathrm{C}$.

We also measured the evolution of the amount of liquid inside the foam with time to follow the drainage (Figure SI.6). After foam formation for all $\mathrm{R}$ and temperatures, the liquid fraction was high around $20+/-5 \%$. No trend for the liquid fraction was observed as a function of R. The liquid fraction quickly decreased with time for all samples, showing that drainage occured whatever R. However, we observed that the drainage rate was faster at $35^{\circ} \mathrm{C}$ than at $15^{\circ} \mathrm{C}$ at $\mathrm{R}<1$. The liquid fraction decreased faster for $\mathrm{R} \geq 1$ for all temperatures.
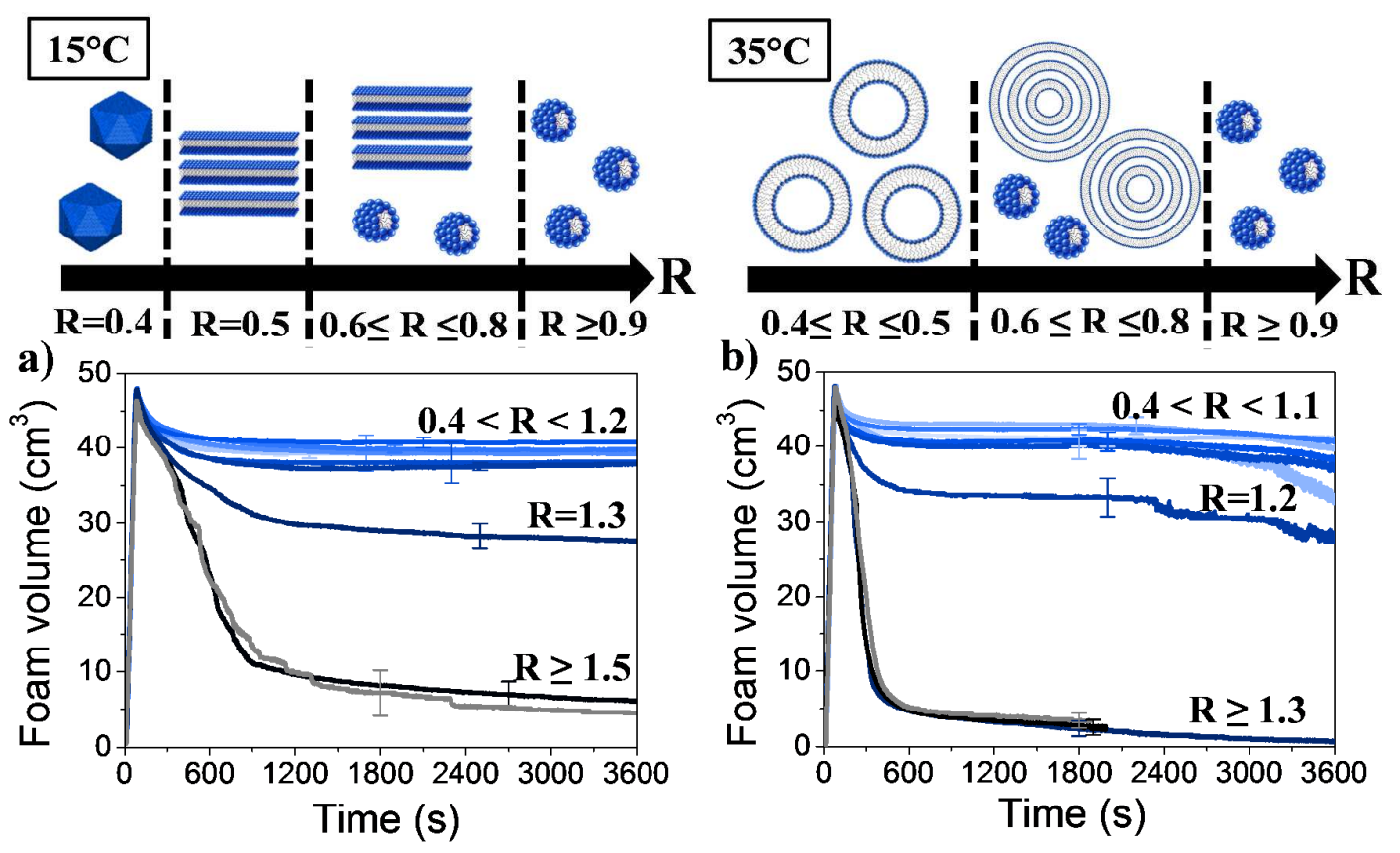

Figure 4: Evolution of the foam volume as a function of time for foams produced by bubbling gas for various molar ratios (R) at two temperatures: (a) $15^{\circ} \mathrm{C}$ and (b) $35^{\circ} \mathrm{C}$. The schematic drawings 
represent the self-assemblies present in bulk as a function of both $\mathrm{R}$ and temperature as determined in a previous study. ${ }^{30}$

It is known in the literature that the foam production method influences the foaming properties. ${ }^{44}$ For comparison, we also produced foams by hand-shaking (Figure 5. a-b).The advantage of shaking is that it can be performed in closed bottles, which permit us to follow the evolution of the foam volume over longer times, 24 hours in our case. Moreover, the use of two different foaming techniques leads to different bubble sizes as well as liquid fractions at the end of the foam production. Hand-shaking was used to confirm the observations made from the bubbling techniques i.e. the three foam stability regimes. After foam formation for all $\mathrm{R}$ and temperatures, the liquid fraction was high around $30+/-5 \%$, for all $\mathrm{R}$ and temperatures. The bubble diameters generated with the handshaking method were larger than with the bubbling method (around 50-100 $\mu \mathrm{m}$ for bubbling and around $150 \mu \mathrm{m}$ for handshaking).

At $15^{\circ} \mathrm{C}$, we obtained again three regimes of foam stability (Figure 5.a). For $0.4<\mathrm{R} \leq 1.1$, the foam volume slightly decreased after 24 hours of conservation of the foam at $15^{\circ} \mathrm{C}$. For $\mathrm{R}=1.1$, after 24 hours, the foam volume decreased from around $12 \mathrm{~cm}^{3}$ to $3 \mathrm{~cm}^{3}$, and the bubble size increased as seen by naked eye. For $\mathrm{R} \geq 1.3$, there was almost no more foam after only one hour. At $35^{\circ} \mathrm{C}$, whatever $\mathrm{R}$, there was no more foam after 24 hours (Figure 5.b). After 5 hours, three regimes of foam stability were again observed. For $0.4<\mathrm{R} \leq 1$, the foams were stable with a foam volume decrease of only few $\mathrm{cm}^{3}$ after 5 hours of conservation of the foam. For $\mathrm{R}=1.1$, after 5 hours, the foam had an intermediate stability since the foam volume decreased from around $12 \mathrm{~cm}^{3}$ to $3 \mathrm{~cm}^{3}$ accompanied by an increase of the bubbles size. For $\mathrm{R} \geq 1.2$, the foams were unstable with no more foam after only one hour; only few very big bubbles remained present inside the plastic tube. The same trend was observed at $25^{\circ} \mathrm{C}$, stable foams for $0.4<\mathrm{R}<1$, intermediate stability for $1 \leq \mathrm{R} \leq 1.1$, and unstable foams for $\mathrm{R} \geq 1.2$ (Figure SI.7).

Between the two foaming methods, we observed that the results were quite close and three main regimes were distinguished for the evolution of the foam volume over time as a function of R. However, the onset of the transition between stable foams and intermediate stability was shifted to lower $\mathrm{R}$ values in the case of foams produced by handshaking in comparison to foams produced by bubbling, a trend that was observed for all temperatures. This shows that 
the initial bubbles size and liquid fraction had a slight effect on the $\mathrm{R}$ threshold values between the three regimes.
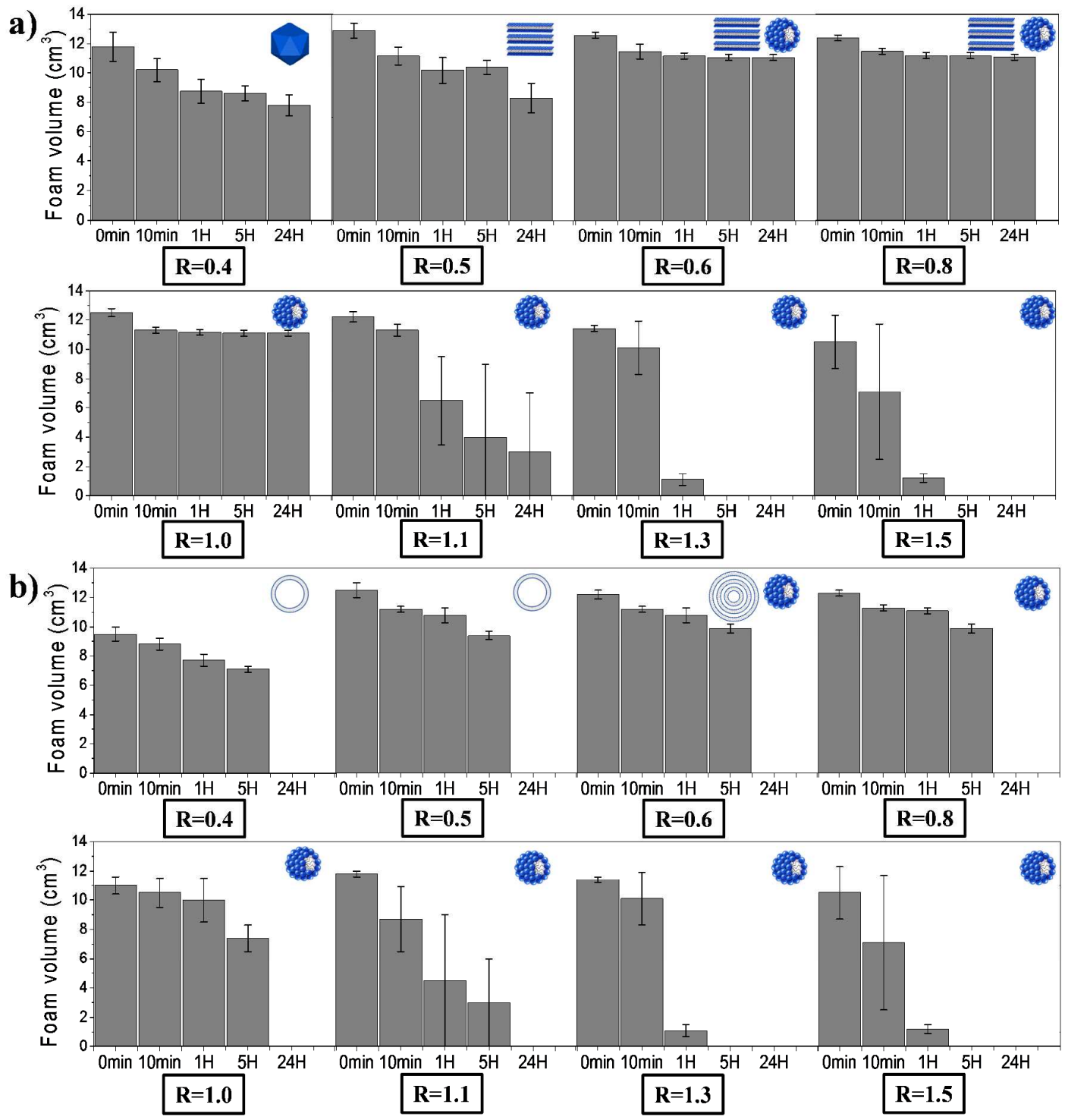

Figure 5: Evolution of the foam volume as a function of time for foams produced by hand-shaking for various molar ratios (R) at two temperatures: (a) $15^{\circ} \mathrm{C}$ and (b) $35^{\circ} \mathrm{C}$. The schematics represent the self-assemblies present in bulk as a function of both $\mathrm{R}$ and the temperature.

\section{Discussion: links between self-assembly in bulk, interfacial and foam properties as a function of $R$}


The results we have gathered at all the different scales from the molecular to the macroscopic scale show that : $(i)$ Three different regimes of surface tension were observed, which are strongly linked to $\mathrm{R}$ and therefore to $\mathrm{pH}$; $(i i)$ the foamability does not depend on $\mathrm{R}$; (iii) the foam stability is tuned by $\mathrm{R}$ and three regimes of foam stability are obtained, respectively high, medium and low; (iv) Inside the foam liquid channels, the structure of the self-assembled nanostructures are identical to those in bulk and are tuned by R. This combination of results should allow us to depict the mechanisms that lead to the three foam stability regimes observed by addressing the following questions: Does it come from changes of the bulk or interfacial properties, or both? Is the foam stability driven by the bulk or the interfacial properties? What sets the transitions between high, medium and low foam stability regimes?

It is well known that the destabilization of foams occurs due to three main mechanisms: coalescence, coarsening and drainage. ${ }^{25,49,50}$ Here, we observed that the foam drainage was slightly slower in the presence of self-assembled bilayer structures than in the presence of spherical micelles. This difference in drainage rate comes from a much higher bulk viscosity for the dispersions containing vesicles, lamellar phases, etc. than for spherical micelles (Figure SI.8). ${ }^{51,52}$ However, even in the case of foams produced at low R containing micronsize aggregates, the foam drainage occurred leading to relatively dry foams after less than one hour for foams produced by bubbling (liquid fraction below $5 \%$ ), even if such foams show a very good stability. Therefore, the foam stability was mainly linked to coalescence and coarsening phenomena in our model system, and not to the drainage.

To limit the coalescence and coarsening phenomena, the mechanical properties of the interfacial layers such as the resistance to the compression and the elasticity are important. In the literature, it is described that the surface properties are linked to the ionization state of the fatty acid molecules in bulk, which is controlled by the $\mathrm{pH} \cdot{ }^{25,50}$ For fatty acid monolayers, the difference in $\mathrm{pKa}$ between the surface and the bulk is small. When the $\mathrm{pH}$ is close to the $\mathrm{pKa}$, the fatty acids are present both under protonated and deprotonated states in 1:1 proportion in bulk. $^{5,6,53}$

In our system, for $0.4<\mathrm{R} \leq 1$, low surface tensions were obtained. The $\mathrm{pH}$ in bulk was around 9 corresponding to the pKa of the myristic acid. Based on the results obtained in similar systems in the literature, we can suppose that at the air/water interface, protonated and deprotonated molecules under ionized state are both present. ${ }^{7,54,55} \mathrm{We}$ suppose that there is a synergistic adsorption of both molecular species and they interact by hydrogen bonding, 
causing a reduction of the intermolecular distance leading to a dense monolayer at the interface. In the literature, it is known that the presence of carboxylic group at the interface decreases the electrostatic repulsive forces leading to a tighter monolayer packing. ${ }^{7,54,55}$ This dense monolayer formed by both species at the interface gives rise to an elastic surfactant layer as highlighted in similar systems. ${ }^{22-24}$ When the $\mathrm{pH}$ in bulk increases by increasing $\mathrm{R}$, the protonated myristic acid molecules progressively become deprotonated. At the interface, the ratio of deprotonated molecules to protonated in the monolayer increases, which increases the electrostatic repulsions between the charged carboxylate headgoups. This reduces the density of fatty acids that can be adsorbed compared to what happens at lower R. Consequently, for $1<\mathrm{R}<1.2$ the surface tension increases progressively in accordance to the decrease of fatty acids surface density. For $\mathrm{R}>1.3$ corresponding to high $\mathrm{pH}$, only deprotonated molecules are present both in bulk and at the interface. The strong repulsive forces between the carboxylate headgroups are maximal and the adsorption density is minimal and lower than at $\mathrm{pH}$ close to the $\mathrm{pKa}$ (Figure 6). ${ }^{56}$ In such range of $\mathrm{R}$, the surface tension reaches its highest values due to low density of fatty acid molecules at the interface. Similar results have been described in the literature for sodium salt of myristic acid by coupling surface tension and Infrared Absorption Spectroscopy. ${ }^{54}$ Thus, three different ranges of surface tension exist as a function of $\mathrm{R}$ : low for $\mathrm{R}<1$, intermediate for $\mathrm{R} \approx 1$ and high for $\mathrm{R} \gg>1$ (Figure 6). The intermediate regime corresponds to the transition between the low surface tension regime to the high surface tension regime due to the progressive deprotonation of the fatty acid molecules. The transition between these two extremes is smooth.

It has recently been suggested that the ability of surfactants to form hydrogen bonds at the interface tunes the stability of foam films and therefore to the overall stability of the foam at the macroscopic scale. ${ }^{24}$ Since we have identified on our model system three ranges of $\mathrm{R}$ for the surface tension, we can discuss their respective influences on three different regimes of foam stability identified as a function of $\mathrm{R}$ : high for $\mathrm{R}<1$, intermediate for $\mathrm{R} \approx 1$ and low for $\mathrm{R}>>1$ (Figure 6).

\section{High foam stability regime for $R$ below equimolarity}

For this high foam stability regime, all the dispersions contained large self-assembled bilayer structures (facetted vesicles, spherical vesicles and lamellar phases) both in bulk and in the foam liquid channels. This high foam stability regime corresponds to the low surface tension regime where a dense monolayer is formed at the interface, which ensures a good protection for the bubbles against coarsening and coalescence. Moreover, we have shown by SNR that 
below this fatty acid monolayer, the facetted vesicles and lamellar phases were adsorbed and formed multilamellar phases at the interface. These structures form thick interface layers, and are known to reinforce the protection of the bubbles since the coarsening is linked to the permeability of the interfacial layer.$^{57-59}$

\section{Low foam stability regime for $\mathbf{R}$ above equimolarity}

The foams obtained from dispersions containing spherical micelles for $\mathrm{R}>>1$ were destroyed quickly with time. We showed that only spherical micelles were present inside the foam liquid channels, which does not reduce drainage due to the low bulk viscosity. This low foam stability regime corresponds also to the high surface tension regime with a monolayer that contains only a low density of fatty acid molecules and cannot protect the bubbles against coalescence and coarsening. The mechanisms of foam destabilization are not blocked resulting in unstable foams.

In this high regime of $\mathrm{R}$, large excess of counter-ions in the foam can affect also its foamability. In this regime, the thin film stability is due to electrostatic repulsion between the ionic double layers associated with the adsorbed ionic surfactants on the two sides of the liquid film. A large addition of choline hydroxide as counter-ion screens these interactions and in turn causes the shortening of the electrical double layers, decreasing the stability of the foam. This fast foam destabilization could also explain why the foamability is lower than for the other R regimes; as destabilization already took place during the foam formation. ${ }^{60}$ This phenomenon has been already described for mixtures between cationic surfactants and organic counter-ions. ${ }^{61,62}$

\section{Intermediate foam stability regime for $\mathrm{R}$ close to the equimolarity}

Our results show that in the vicinity of equimolarity, foams were relatively stable even though only micelles were detected in the bulk foam channels as for the low foam stability regime. This is a proof that the conditions required to obtain stable foams are not only driven by the presence of large self-assembled structures in bulk (vesicles, lamellar phases, etc.), but also to the strong influence of the packing of fatty acids at the surface. This intermediate regime is a smooth crossover between the two extreme regimes (high and low foam stability). For this intermediate foam stability regime, the surface tension regime also corresponds to the 
crossover range of surface packing and surface tension between high and low surface tension. The result at the macroscopic scale is an intermediate foam stability.

\section{Effect of the alkyl chain melting on the phase behavior and foam stability}

In this system, the alkyl chain melting occurs around $27^{\circ} \mathrm{C}$, which has been shown to induce a change in the rigidity of the self-assemblies in bulk from facetted vesicles and lamellar phases to spherical vesicles. ${ }^{30}$ The melting has rather a low influence on the foam stability, as shown by the results obtained below $\left(15\right.$ and $25^{\circ} \mathrm{C}$ ), and above the alkyl chain melting temperature $\left(35^{\circ} \mathrm{C}\right)$. Indeed, the general foam stability trend was not influenced by the state of the chains and for all temperatures, three regimes of foam stability were always observed. However, above $27^{\circ} \mathrm{C}$, the foam stability was lower than below. This transition at the molecular scale mainly modifies the properties of the interfacial layer, where the molten chains are more mobile, less well packed, and have lower resistance to deformation. Therefore, they are less able to resist against coalescence and coarsening and lead to a decrease in the foam stability. 


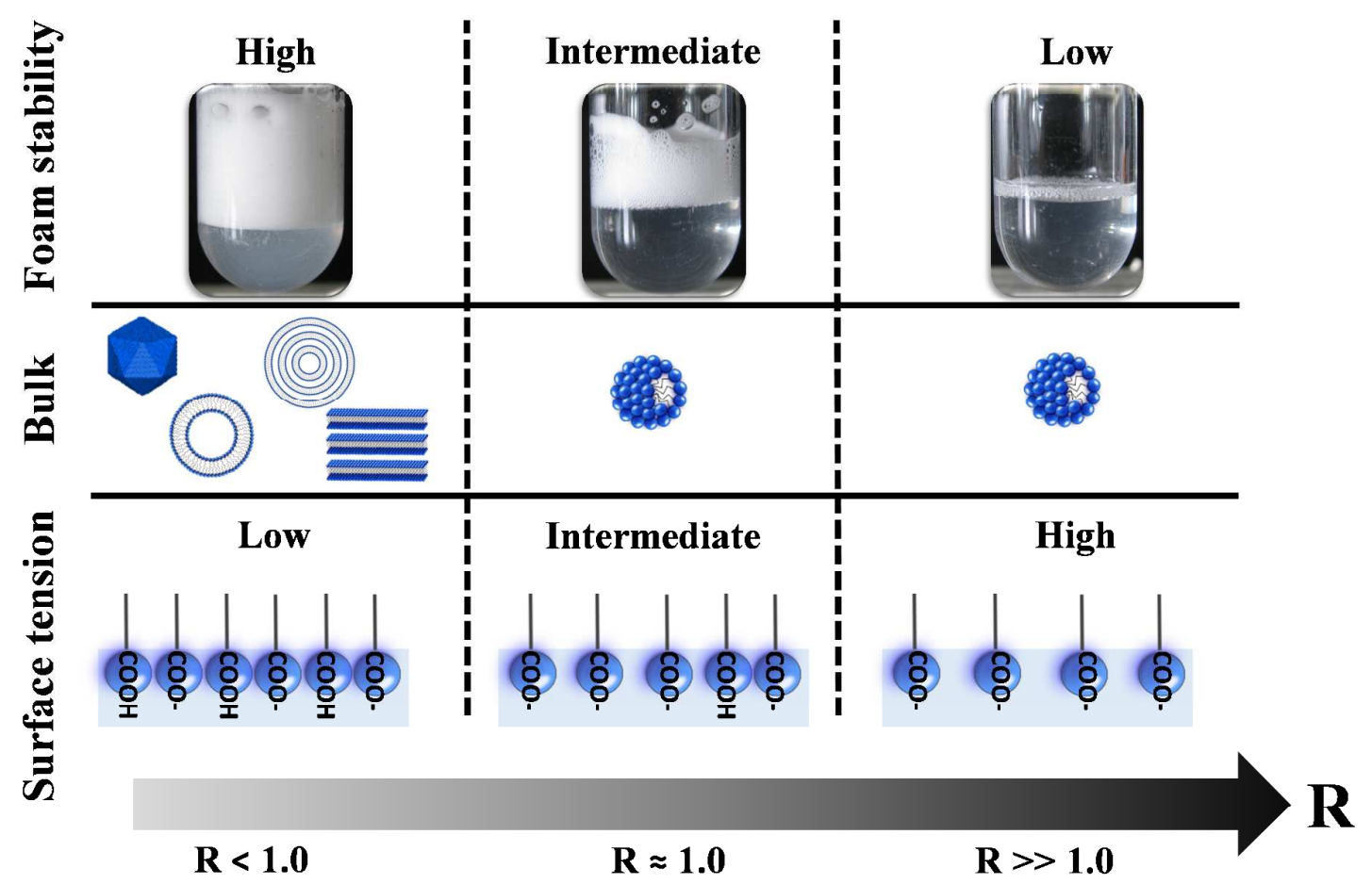

Figure 6: Schematic illustrating the links between the molar ratio (R), the foam stability, the bulk selfassembly, and the surface properties.

\section{Conclusion}

In this study, we demonstrated that it is possible to adjust the foam stability of a system of fatty acids at the macroscopic scale by tuning a simple parameter, the molar ratio $\mathrm{R}$ between the myristic acid and its organic counter-ion the choline hydroxide. Indeed, the tuning of $\mathrm{R}$ induces changes at the molecular scale, which impact at the same time the surface properties, and the self-assembly in the foam liquid channels at the microscopic scale. $\mathrm{R}$ is a simple trigger to tune the foam stability from low to high (Figure 6). By using a multiscale approach, we highlighted that the foam stability could not be explained only by looking at the size and nature of the self-assembly present in bulk, contrary to results described in previous studies in similar fatty acid/organic counter-ion systems. ${ }^{16,}{ }^{18}$ Indeed, we observed either relatively stable foam (close to equimolarity) or unstable foam (above equimolarity) in the presence of the same self-assembly: spherical micelles. Our results confirm recent 
conclusions obtained by Ferreira et al., for catanionic systems, showing that the self-assembly structure is not the only appropriate parameter to predict foam stability. ${ }^{29}$

The difference of foam stability in our system is mainly linked to the properties of the fatty acid monolayer at the interface, which depends on the ionization state of the myristic acid. By controlling the molar ratio $\mathrm{R}$, we can set the $\mathrm{pH}$ of the bulk, which is linked to the quantity of hydroxide ions introduced by the choline hydroxide counter-ion. The $\mathrm{pH}$ governs the ratio between the deprotonated and protonated molecules both in bulk and at the interface, and also the interactions between them: hydrogen bonding and/ or repulsive electrostatic interactions. The surface tension and the density of fatty acids at the interface are directly linked to R. Therefore, we can suppose that the foam stability follows mainly the variation of the interfacial properties governed by $\mathrm{R}$, which plays a crucial role at the molecular scale. This result can be explained by the fact that we are dealing with coalescence and coarsening issues in this system. These foam destabilization mechanisms are happening at the scale of the thin films separating bubbles, which are made of two interfaces in interaction. For fatty acid soap systems, the main requirement to obtain stable foam is to stabilize the bubbles by having a mixture of protonated and deprotonated molecules at the interface interacting by hydrogen bonds giving rise to a dense and elastic surfactant layer counteracting coalescence and coarsening.

Our results seem to be confirming the role of intermolecular hydrogen bonds between surfactant head groups on the foam stability, as demonstrated recently with other types of surfactants. $^{22-24}$ One of the next steps of our study is to confirm the results obtained with myristic acid by using other counter-ions as already described in the literature in the bulk and with other surfactants enable to form hydrogen bonding. ${ }^{63-65}$

This study based on a fatty acid soap system provides new insights to understand the relationships existing between foam stability and self-assembly, which is of interest to all the scientists working on formulation, foam and self-assembly, and will stimulate further works on the subject. From an applied point of view, this study could help to improve the foaming formulations based on fatty acid soaps for various applications in detergency, cosmetics, etc.

\section{$\underline{\text { Acknowledgments }}$}


Dr. A.Arnould would like to thank the region Pays de la Loire and INRA for the allocation of her $\mathrm{PhD}$ grant. The beam time allocation on both the spectrometer PACE and on the reflectometer EROS from the Laboratoire Léon Brillouin was gratefully appreciated. The authors would like to thank Dr. Marc Anton for the useful discussions. The experimental assistance of B. Houinsou-Houssou was greatly appreciated.

\section{References}

1. Fameau, A.-L.; Zemb, T. Self-assembly of fatty acids in the presence of amines and cationic components. Advances in Colloid and Interface Science 2014, 207, 43-64.

2. Wolfrum, S.; Marcus, J.; Touraud, D.; Kunz, W. A renaissance of soaps?-How to make clear and stable solutions at neutral $\mathrm{pH}$ and room temperature. Advances in Colloid and Interface Science 2016, 236, 28-42.

3. Johansson, I.; Svensson, M. Surfactants based on fatty acids and other natural hydrophobes. Current Opinion in Colloid \& Interface Science 2001, 6 (2), 178-188.

4. $\quad$ Chupa, J.; Misner, S.; Sachdev, A.; Wisniewski, P.; Smith, G. A. Soap, Fatty Acids, and Synthetic Detergents. In Handbook of Industrial Chemistry and Biotechnology; Springer, 2012, pp 1431-1471.

5. Kanicky, J. R.; Poniatowski, A. F.; Mehta, N. R.; Shah, D. O. Cooperativity among molecules at interfaces in relation to various technological processes: Effect of chain length on the pK(a) of fatty acid salt solutions. Langmuir 2000, 16 (1), 172-177.

6. Theander, K.; Pugh, R. J. Synergism and foaming properties in mixed nonionic/fatty acid soap surfactant systems. Journal of Colloid and Interface Science 2003, 267 (1), 9-17.

7. Golemanov, K.; Denkov, N. D.; Tcholakova, S.; Vethamuthu, M.; Lips, A. Surfactant mixtures for control of bubble surface mobility in foam studies. Langmuir 2008, 24 (18), 9956-9961.

8. Zhang, Y.; Kong, W.; An, P.; He, S.; Liu, X. CO2/pH-Controllable Viscoelastic Nanostructured Fluid Based on Stearic Acid Soap and Bola-Type Quaternary Ammonium Salt. LANGMUIR 2016, 32 (10), 2311-2320.

9. Miles, G. D.; Ross, J. Foam Stability of Solutions of Soaps of Pure Fatty Acids. The Journal of Physical Chemistry 1944, 48 (5), 280-290.

10. Fameau, A.-L.; Houinsou-Houssou, B.; Ventureira, J.; Navailles, L.; Nallet, F.; Novales, B.; Douliez, J.-P. Self-Assembly, Foaming, and Emulsifying Properties of Sodium Alkyl Carboxylate/Guanidine Hydrochloride Aqueous Mixtures. Langmuir 2011, 27 (8), 4505-4513.

11. Fameau, A.-L.; Saint-Jalmes, A.; Cousin, F.; Houssou, B. H.; Novales, B.; Navailles, L.; Nallet, F.; Gaillard, C.; Boue, F.; Douliez, J.-P. Smart Foams: Switching Reversibly between Ultrastable and Unstable Foams. Angewandte Chemie-International Edition 2011, 50 (36), 8264-8269.

12. Fameau, A.-L.; Ventureira, J.; Novales, B.; Douliez, J.-P. Foaming and emulsifying properties of fatty acids neutralized by tetrabutylammonium hydroxide. Colloids and Surfaces A: Physicochemical and Engineering Aspects 2012, 403, 87-95.

13. Fameau, A.-L.; Gaillard, C.; Marion, D.; Bakan, B. Interfacial properties of functionalized assemblies of hydroxy-fatty acid salts isolated from fruit tomato peels. Green Chemistry 2013, 15 (2), 341-346.

14. Xu, W.; Gu, H.; Zhu, X.; Zhong, Y.; Jiang, L.; Xu, M.; Song, A.; Hao, J. CO2-controllable foaming and emulsification properties of the stearic acid soap systems. Langmuir 2015, 31 (21), 57585766. 
15. Shu, X.; Meng, Y.; Wan, L.; Li, G.; Yang, M.; Jin, W. pH-Responsive Aqueous Foams of Oleic Acid/Oleate Solution. Journal of Dispersion Science and Technology 2013, (just-accepted).

16. Novales, B.; Riaublanc, A.; Navailles, L.; Houssou, B. H.; Gaillard, C.; Nallet, F.; Douliez, J. P. Self-Assembly and Foaming Properties of Fatty Acid-Lysine Aqueous Dispersions. Langmuir 2010, 26 (8), 5329-5334.

17. Li, G.; Yang, Q.; Song, A.; Hao, J. Self-assembled structural transition from vesicle phase to sponge phase and emulsifying properties in mixtures of arginine and fatty acids. Colloids and Surfaces A: Physicochemical and Engineering Aspects 2015, 487, 198-206.

18. Novales, B.; Navailles, L.; Axelos, M.; Nallet, F.; Douliez, J. P. Self-assembly of fatty acids and hydroxyl derivative salts. Langmuir 2008, 24 (1), 62-68.

19. Xu, W.; Liu, H.; Song, A.; Hao, J. Bilayers and wormlike micelles at high pH in fatty acid soap systems. Journal of Colloid and Interface Science 2016, 465, 304-310.

20. Fameau, A.-L.; Salonen, A. Effect of particles and aggregated structures on the foam stability and aging. Comptes Rendus Physique 2014.

21. Douliez, J.-P.; Gaillard, C. Self-assembly of fatty acids: from foams to protocell vesicles. New Journal of Chemistry 2014, 38 (11), 5142-5148.

22. Ranieri, D.; Preisig, N.; Stubenrauch, C. On the Influence of Intersurfactant H-Bonds on Foam Stability: A Study with Technical Grade Surfactants. Tenside Surfactants Detergents 2018, 55 (1), 6 16.

23. Schellmann, K.; Preisig, N.; Claesson, P.; Stubenrauch, C. Effects of protonation on foaming properties of dodecyldimethylamine oxide solutions: a pH-study. Soft Matter 2015, 11 (3), 561-571.

24. Stubenrauch, C.; Hamann, M.; Preisig, N.; Chauhan, V.; Bordes, R. On how hydrogen bonds affect foam stability. Advances in Colloid and Interface Science 2017, 247, 435-443.

25. Pugh, R. J. Bubble and foam chemistry; Cambridge University Press2016.

26. Fauser, H.; Uhlig, M.; Miller, R.; Klitzing, R. v. Surface adsorption of oppositely charged SDS: C12TAB mixtures and the relation to foam film formation and stability. The Journal of Physical Chemistry B 2015, 119 (40), 12877-12886.

27. Langevin, D. Influence of interfacial rheology on foam and emulsion properties. Advances in Colloid and Interface Science 2000, 88 (1), 209-222.

28. Prud'homme, R. Foams: Theory: Measurements: Applications; Routledge2017.

29. Ferreira, J.; Mikhailovskaya, A.; Chennevière, A.; Restagno, F.; Cousin, F.; Muller, F.; Degrouard, J.; Salonen, A.; Marques, E. F. Interplay between Bulk Self-Assembly, Interfacial and Foaming Properties in a Catanionic Surfactant Mixture of Varying Composition. Soft Matter 2017.

30. Arnould, A.; Perez, A. A.; Gaillard, C.; Douliez, J.-P.; Cousin, F.; Santiago, L. G.; Zemb, T.; Anton, M.; Fameau, A.-L. Self-assembly of myristic acid in the presence of choline hydroxide: Effect of molar ratio and temperature. Journal of Colloid and Interface Science 2015, 445, 285-293.

31. Klein, R.; Touraud, D.; Kunz, W. Choline carboxylate surfactants: biocompatible and highly soluble in water. Green Chemistry 2008, 10 (4), 433-435.

32. Klein, R.; Kellermeier, M.; Drechsler, M.; Touraud, D.; Kunz, W. Solubilisation of stearic acid by the organic base choline hydroxide. Colloids and Surfaces a-Physicochemical and Engineering Aspects 2009, 338 (1-3), 129-134.

33. Klein, R.; Tiddy, G. J.; Maurer, E.; Touraud, D.; Esquena, J.; Tache, O.; Kunz, W. Aqueous phase behaviour of choline carboxylate surfactants - exceptional variety and extent of cubic phases. Soft Matter 2011, 7 (15), 6973-6983.

34. Wei, Y.; Wang, H.; Liu, G.; Wang, Z.; Yuan, S. A molecular dynamics study on two promising green surfactant micelles of choline dodecyl sulfate and laurate. RSC Advances 2016, 6 (87), 84090-84097.

35. Li, G.; Liu, Y.; Xu, W.; Song, A.; Hao, J. Transition of phase structures in mixtures of lysine and fatty acids. The Journal of Physical Chemistry B 2014, 118 (51), 14843-14851.

36. Dubois, M.; Demé, B.; Gulik-Krzywicki, T.; Dedieu, J.-C.; Vautrin, C.; Désert, S.; Perez, E.; Zemb, T. Self-assembly of regular hollow icosahedra in salt-free catanionic solutions. Nature 2001, 411 (6838), 672-675.

37. Zemb, T.; Dubois, M.; Deme, B.; Gulik-Krzywicki, T. Self-assembly of flat nanodiscs in saltfree catanionic surfactant solutions. Science 1999, 283 (5403), 816-819. 
38. Zana, R. Partial phase behavior and micellar properties of tetrabutylammonium salts of fatty acids: Unusual solubility in water and formation of unexpectedly small micelles. Langmuir 2004, 20 (14), 5666-5668.

39. Zana, R.; Schmidt, J.; Talmon, Y. Tetrabutylammonium alkyl carboxylate surfactants in aqueous solution: Self-association behavior, solution nanostructure, and comparison with tetrabutylammonium alkyl sulfate surfactants. Langmuir 2005, 21 (25), 11628-11636.

40. Wang, Y.; Jiang, L.; Shen, Q.; Shen, J.; Han, Y.; Zhang, H. Investigation on the selfassembled behaviors of $\mathrm{C} 18$ unsaturated fatty acids in arginine aqueous solution. RSC Advances 2017, 7 (66), 41561-41572.

41. Fan, Y.; Ma, J.; Fang, Y.; Liu, T.; Hu, X.; Xia, Y. Neutral and acid-adapted fatty acid vesicles of conjugated linoleic acid. Colloids and Surfaces B: Biointerfaces 2018, 167, 385-391.

42. Brûlet, A.; Lairez, D.; Lapp, A.; Cotton, J.-P. Improvement of data treatment in small-angle neutron scattering. Journal of Applied Crystallography 2007, 40 (1), 165-177.

43. Mikhailovskaya, A.; Zhang, L.; Cousin, F.; Boué, F.; Yazhgur, P.; Muller, F.; Gay, C.; Salonen, A. Probing foam with neutrons. Advances in Colloid and Interface Science 2017, 247, 444453.

44. Drenckhan, W.; Saint-Jalmes, A. The science of foaming. Advances in Colloid and Interface Science 2015, 222, 228-259.

45. Penfold, J.; Thomas, R. K. Neutron reflectivity and small angle neutron scattering: an introduction and perspective on recent progress. Current Opinion in Colloid \& Interface Science 2014, 19 (3), 198-206.

46. Fameau, A.-L.; Douliez, J.-P.; Boue, F.; Ott, F.; Cousin, F. Adsorption of multilamellar tubes with a temperature tunable diameter at the air/water interface. Journal of Colloid and Interface Science 2011, 362 (2), 397-405.

47. Curschellas, C.; Kohlbrecher, J.; Geue, T.; Fischer, P.; Schmitt, B.; Rouvet, M.; Windhab, E. J.; Limbach, H. J. r. Foams Stabilized by Multilamellar Polyglycerol Ester Self-Assemblies. Langmuir 2012, 29 (1), 38-49.

48. Penfold, J. Neutron scattering for surface characterization. Current Science 2000, 78 (12), $1458-1466$.

49. Cantat, I.; Cohen-Addad, S.; Elias, F.; Graner, F.; Höhler, R.; Pitois, O.; Rouyer, F.; SaintJalmes, A. Foams: structure and dynamics; OUP Oxford2013.

50. Pugh, R. J. Foaming, foam films, antifoaming and defoaming. Advances in Colloid and Interface Science 1996, 64, 67-142.

51. Safouane, M.; Saint-Jalmes, A.; Bergeron, V.; Langevin, D. Viscosity effects in foam drainage: Newtonian and non-newtonian foaming fluids. The European Physical Journal E 2006, 19 (2), 195-202.

52. Stoyanov, S.; Dushkin, C.; Langevin, D.; Weaire, D.; Verbist, G. Effect of the rheology on foam drainage. LANGMUIR 1998, 14 (16), 4663-4665.

53. Chen, L.-C.; Wang, H.-P.; Deng, Y.-H.; Deng, S.-P. Vesicle formation by proton transfer driven short-tailed fatty acids of C4-C8 chain length in water. Soft Matter 2017, 13 (6), 1291-1298.

54. Wen, X. Y.; Lauterbach, J.; Franses, E. I. Surface densities of adsorbed layers of aqueous sodium myristate inferred from surface tension and infrared reflection absorption spectroscopy. Langmuir 2000, 16 (17), 6987-6994.

55. Yim, K. S.; Rahaii, B.; Fuller, G. G. Surface rheological transitions in Langmuir monolayers of bi-competitive fatty acids. Langmuir 2002, 18 (17), 6597-6601.

56. Coltharp, K. A.; Franses, E. I. Equilibrium and dynamic surface tension behavior of aqueous soaps: Sodium octanoate and sodium dodecanoate (sodium laurate). Colloids and Surfaces aPhysicochemical and Engineering Aspects 1996, 108 (2-3), 225-242.

57. Varade, D.; Carriere, D.; Arriaga, L.; Fameau, A.-L.; Rio, E.; Langevin, D.; Drenckhan, W. On the origin of the stability of foams made from catanionic surfactant mixtures. Soft Matter 2011, 7 (14), 6557-6570.

58. Briceño-Ahumada, Z.; Langevin, D. On the influence of surfactant on the coarsening of aqueous foams. Advances in Colloid and Interface Science 2017, 244, 124-131.

59. Georgieva, D.; Cagna, A.; Langevin, D. Link between surface elasticity and foam stability. Soft Matter 2009, 5 (10), 2063-2071. 
60. Carrier, V.; Colin, A. Coalescence in draining foams. Langmuir 2003, 19 (11), 4535-4538.

61. Kristen-Hochrein, N.; Schelero, N.; Von Klitzing, R. Effects of oppositely charged surfactants on the stability of foam films. Colloids and Surfaces A: Physicochemical and Engineering Aspects 2011, 382 (1), 165-173.

62. Blute, I.; Jansson, M.; Oh, S.; Shah, D. The molecular mechanism for destabilization of foams by organic ions. Journal of the American Oil Chemists' Society 1994, 71 (1), 41-46.

63. Arnould, A.; Cousin, F.; Chabas, L.; Fameau, A.-L. Impact of the molar ratio and the nature of the counter-ion on the self-assembly of myristic acid. Journal of Colloid and Interface Science 2017.

64. Fameau, A.-L.; Arnould, A.; Lehmann, M.; von Klitzing, R. Photoresponsive self-assemblies based on fatty acids. Chemical Communications 2015, 51 (14), 2907-2910.

65. Chiappisi, L. Polyoxyethylene alkyl ether carboxylic acids: an overview of a neglected class of surfactants with multiresponsive properties. Advances in Colloid and Interface Science 2017. 